\title{
Screening on the sorption of emerging contaminants to polystyrene and polyethylene and use of coagulation - flocculation process for microplastics' removal
}

\author{
Arvaniti O.S. ${ }^{1,2}$, Antonopoulou G. ${ }^{1,3}$, Tsagkogianni D. ${ }^{1}$ and Stasinakis A.S. ${ }^{1 *}$ \\ ${ }^{1}$ Water and Air Quality Laboratory, Department of Environment, University of the Aegean, Mytilene 81100, Greece \\ 2Department of Chemical Engineering, University of Patras, Caratheodory 1, University Campus, Patras 26504, Greece \\ ${ }^{3}$ Institute of Chemical Engineering Sciences, 11 Stadiou St., Platani, Patras 26504, Greece \\ Received: 28/06/2021, Accepted: 23/07/2021, Available online: 15/08/2021 \\ *to whom all correspondence should be addressed: e-mail: astas@env.aegean.gr \\ https://doi.org/10.30955/gnj.003854
}

\section{Graphical abstract}

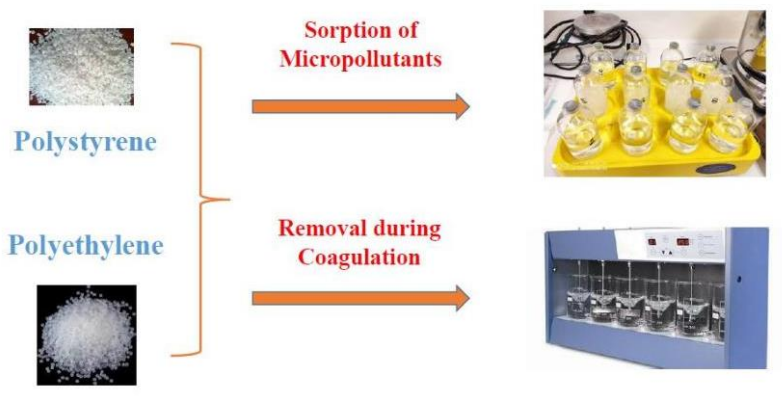

\begin{abstract}
In this study, preliminary experiments were conducted to investigate the sorption potential of different organic micropollutants to polystyrene and polyethylene and to examine the removal efficiency of these microplastics during coagulation experiments with iron and manganese coagulants. For the sorption experiments, eight synthetic chemicals which belong to three different categories, pharmaceutical compounds, personal care products and endocrine-disrupting compounds were used. Among target compounds, important removal due to sorption to microplastics was noticed for the antihypertensive drugs valsartan and losartan, when polystyrene was used as sorbent material. Their sorption was a slow and gradual process; $20 \%$ of valsartan and $59 \%$ of losartan was sorbed after $168 \mathrm{~h}$. On the other hand, no sorption of parabens, bisphenol $A$ and sulfamethoxazole was observed. The elaboration of coagulation experiments showed that polystyrene is removed to a higher percentage comparing to polyethylene, reaching $92.4 \%$ and $72.1 \%$, respectively. The higher removal of polystyrene was achieved when ferrous sulfate or magnesium sulfate was added, while the use of ferric chloride did not improve its removal. Increased removal of polyethylene was achieved when magnesium sulfate was used. Further experiments should
\end{abstract}

be conducted to investigate the parameters affecting sorption of valsartan and losartan to microplastics and the mechanisms governing removal of polystyrene and polyethylene during coagulation.

Keywords: Microplastics, water, removal, coagulation, sorption, micropollutants.

\section{Introduction}

Plastic pollution is a major issue of global concern and has received ever-increasing attention over the last decade. Microplastics, MPs (plastic fragments $<5 \mathrm{~mm}$ ) are intentionally manufactured or formed by larger plastics debris breakdown in the environment (Gatidou et al., 2019; Tziourrou et al., 2021). Their existence has been reported worldwide and the deleterious effects from their physical accumulation on different organisms have been highlighted (Chae et al., 2017; Paul-Pont et al., 2018). Their tension to sorb and transport toxic chemicals, their durability in nature, and their capacity to be transferred within food chain, render adverse effects more intense (Gatidou et al., 2019). During the last five years, MPs have been detected in drinking water, raw and treated wastewater, as well as in sewage sludge, worldwide (BenDavid et al., 2020; Murphy et al., 2016).

Among different MPs, polystyrene (PS) and polyethylene (PE) are two important categories that are widely used in numerous applications. PS is often used in products that require clarity, such as laboratory ware and food packaging. When combined with various colorants or other plastics, PS is used to make automobile parts, electronics, toys and gardening pots. PE is used in several packaging applications such as trays, crates, bottles for juices and milk, in household/consumer goods as well as in fibers and textiles. Previous studies have shown the common detection of PS and PE in water and wastewater samples. According to Andrady (2011), PE is considered the main MP detected in water. Compared with plastics that are much denser than water, PS and PE are more 
likely to enter people's lives and lead to potential threats as they have similar densities to the natural water.

Previous studies have shown the tension of PS and PE to sorb organic micropollutants belonging to different groups such as polycyclic aromatic hydrocarbons (Karapanagioti et al., 2010; Yu et al., 2020) and polybrominated diphenyl ethers (Singla et al., 2020). On the other hand, limited information is, so far, available for the sorption of pharmaceuticals (PhCs), personal care products (PPCPs), and endocrine disrupting compounds (EDCs) to PS and PE. Among different PPCPs, parabens is an important category. These compounds are esterified molecules of hydroxybenzoic acid at the C-4 position and they are used, due to their antimicrobial properties, as pharmaceutical, food, and cosmetic preservatives. Among them, methyl-, ethyl-, propyl-, butyl-, and benzyl-paraben are the most commonly used compounds. Their environmental concentrations range from $\mathrm{ng} \mathrm{L}^{-1}$ to $\mu \mathrm{g} \mathrm{L}^{-1}$ in the surface waters and the wastewater, respectively. Recent studies have raised concerns about the use of parabens, with special focus on propyl-paraben as possibly having estrogenic potential (Wei et al., 2021). Concerning PhCs, valsartan (VAL) and losartan (LOS) are commonly used antihypertensive drugs. After their consumption, they are partially metabolized in the human body and as a result an important amount of the parent compound is excreted unchanged through the urine. They have been detected in the aquatic environment at concentrations ranging between few $\mathrm{ng} \mathrm{L}^{-1}$ (seawater) to more than $2700 \mathrm{ng} \mathrm{L}^{-1}$ (wastewater) (Kaur and Dulova, 2020). Sulfamethoxazole (SMX) is a sulfonamide bacteriostatic antibiotic, while bisphenol A (BPA) is a chemical used in the production of epoxy resins and plastics with known endocrine disruptive properties (Rubin, 2011).

During the last years, several articles have been published on the fate and removal efficiency of MPs in drinking water treatment plants (Cheng et al., 2021; Pivokonský et al., 2020). Coagulation-flocculation process is widely used during water and wastewater treatment due to its relatively low cost and the ability to remove suspended solids, natural organic matter, color and turbidity (Arukula et al., 2018; Dayarathne et al., 2021; Jiang et al., 2012). Among different coagulants, those based on aluminum and those based on iron are commonly used for the removal of major pollutants. The aluminum coagulants include aluminum sulfate, aluminum chloride and sodium aluminate. The iron coagulants include ferric sulfate, ferrous sulfate, ferric chloride and ferric chloride sulfate (Bratby, 2016). Concerning the removal of MPs, so far, the published articles have tested the use of aluminum based coagulants for PS and PE removal (Laponte et al., 2020; Xue et al., 2021), while limited information is available for the use of iron and magnesium coagulants.

Based to the above, in this research, screening experiments to investigate the sorption potential of different groups of emerging contaminants onto PS and $P E$, were initially conducted. For this reason, experiments were conducted with eight (8) micropollutants belonging to the groups of PhCs (VAL, LOS, SMX), PPCPs (methyl paraben, methyl-P, ethyl paraben, ethyl-P, propyl paraben, propyl-P, butyl paraben, butyl-P) and EDCs (BPA). Afterwards, the removal efficiency of PS and PE from water was studied using coagulation-flocculation process. For this reason, three different coagulants were tested, namely, ferric chloride hexahydrate $\left(\mathrm{FeCl}_{3} \times 6 \mathrm{H}_{2} \mathrm{O}\right)$, ferrous sulfate heptahydrate $\left(\mathrm{FeSO}_{4} \times 7 \mathrm{H}_{2} \mathrm{O}\right)$, magnesium sulfate heptahydrate $\left(\mathrm{MgSO}_{4} \times 7 \quad \mathrm{H}_{2} \mathrm{O}\right)$. The role of coagulant dose on MPs' removal was investigated and the following steps for further research on the field were determined.

\section{Materials and methods}

\subsection{Chemical and reagents}

LOS, VAL, SMX, BPA, methyl-P, ethyl-P, propyl-P, butyl-P, hydrochloric acid $(\mathrm{HCl})$, phosphoric acid $\left(\mathrm{H}_{3} \mathrm{PO} 4\right)$, sodium hydroxide $(\mathrm{NaOH})$, sodium chloride $(\mathrm{NaCl})$, calcium chloride $\left(\mathrm{CaCl}_{2}\right)$, ferrous chloride hexahydrate $\left(\mathrm{FeCl}_{3} \times\right.$ $\left.6 \mathrm{H}_{2} \mathrm{O}\right)$, ferric sulfate heptahydrate $\left(\mathrm{FeSO}_{4} \times 7 \mathrm{H}_{2} \mathrm{O}\right)$, magnesium sulfate heptahydrate $\left(\mathrm{MgSO}_{4} \times 7 \mathrm{H}_{2} \mathrm{O}\right)$, methanol $\left(\mathrm{CH}_{3} \mathrm{OH}\right)$ and acetonitrile $(\mathrm{ACN})$ were supplied by Sigma-Aldrich. The two types of MPs, PS were purchased from Sigma-Aldrich and were crushed to less than $1 \mathrm{~mm}$ with a crusher. The studied MPs were sieved through different meshes and they were divided in fractions of different size. The particles that were used in the current experiments had a size that ranged between 53 and $500 \mu \mathrm{m}$ for PS and a size between 500 and 1000 $\mu \mathrm{m}$ for PE. During sorption experiments, the samples were filtered with $0.45 \mu \mathrm{m}$ polypropylene filters, while in coagulation experiments with $1.6 \mu \mathrm{m}$ LLG-Glass microfibre filters.

\subsection{Sorption experiments}

Batch experiments were initially performed to check the tension of target micropollutants to sorb onto the studied MPs. For this reason, $1000 \mathrm{mg} \mathrm{L}^{-1}$ of PS or PE were added to serum bottles containing $100 \mathrm{~mL}$ of bottled drinking water and $1 \mathrm{mM} \mathrm{NaN}_{3}$ was added to prevent microbial degradation. The target micropollutants (VAL, LOS, SMX, BPA, methyl-P, ethyl-P, propyl-P, and butyl-P) were spiked at an initial concentration of $500 \mu \mathrm{g} \mathrm{L}^{-1}$. The serum bottles were capped and wrapped with aluminum foil to prevent any potential photochemical reactions during mixing and were agitated horizontally at $150 \mathrm{rpm}$ and $25^{\circ} \mathrm{C}$ for $168 \mathrm{~h}$. Samples were collected using glass syringes at the start of the experiment, after $72 \mathrm{~h}$ and at $168 \mathrm{~h}$ and they were filtered to remove MPs. The filtered aqueous samples were stored in the dark at $4{ }^{\circ} \mathrm{C}$ until analysis. Control experiments (with no addition of MPs) were also prepared under the same testing conditions to determine possible abiotic degradation or sorption of studied micropollutants to the serum bottles. During all experiments, the $\mathrm{pH}$ was remained stable at $7.5 \pm 0.1$. No addition of buffer solution was required for $\mathrm{pH}$ adjustment.

\subsection{Coagulation experiments}

Coagulation experiments were conducted using a Jar Tester. In each flask, $400 \mathrm{~mL}$ of tap water were added as well the studied MPs at a final concentration of $500 \mathrm{mg} \mathrm{L}^{-1}$. 
Two doses of coagulants were tested in order to achieve concentrations of 100 and $200 \mathrm{mg} \mathrm{L}^{-1}$ of $\mathrm{Fe}^{3+}, \mathrm{Fe}^{2+}$ or $\mathrm{Mg}^{2+}$.
The added concentrations of different coagulants are shown in Table 1.

Table 1. Concentrations of the coagulants used in the coagulation-flocculation experiments with microplastics (MPs)

\begin{tabular}{ccc}
\hline Tested coagulant & \multicolumn{2}{c}{ Added concentrations } \\
\cline { 2 - 3 } $\mathrm{FeSO}_{4} \times 7 \mathrm{H}_{2} \mathrm{O}$ & $496 \mathrm{mg} \mathrm{L}^{-1}$ & $100 \mathrm{mg} \mathrm{L}^{-1} \mathrm{as} \mathrm{Fe}^{2+}$ \\
\cline { 2 - 3 } & $993 \mathrm{mg} \mathrm{L}^{-1}$ & $200 \mathrm{mg} \mathrm{L}^{-1} \mathrm{as} \mathrm{Fe}^{2+}$ \\
\cline { 2 - 3 } $\mathrm{FeCl}_{3} \times 6 \mathrm{H}_{2} \mathrm{O}^{1}$ & $483 \mathrm{mg} \mathrm{L}^{-1}$ & $100 \mathrm{mg} \mathrm{L}^{-1} \mathrm{as} \mathrm{Fe}^{3+}$ \\
\hline \multirow{2}{*}{$\mathrm{MgSO}_{4} \times 7 \mathrm{H}_{2} \mathrm{O}$} & $964 \mathrm{mg} \mathrm{L}^{-1}$ & $200 \mathrm{mg} \mathrm{L}^{-1} \mathrm{as} \mathrm{Fe}^{3+}$ \\
\cline { 2 - 3 } & $1025 \mathrm{mg} \mathrm{L}^{-1}$ & $100 \mathrm{mg} \mathrm{L}^{-1} \mathrm{as} \mathrm{Mg}^{2+}$ \\
\hline
\end{tabular}

In experiments with $P E$, only the highest concentration of ferrous chloride hexahydrate was tested

The stirring speed was maintained at $300 \mathrm{rpm} / \mathrm{min}$ for 1 $\mathrm{min}$, and then decreased to $50 \mathrm{rpm} / \mathrm{min}$ for $15 \mathrm{~min}$, with a subsequent 30 min sedimentation. After floccuation and sedimentation, $200 \mathrm{~mL}$ from the supernatant of the system was collected for subsequent filtering using glass microfiber filter paper, drying at $60{ }^{\circ} \mathrm{C}$ for $24 \mathrm{~h}$ and weighing. All experiments were conducted in triplicates at $18 \pm 2{ }^{\circ} \mathrm{C}$. The initial water $\mathrm{pH}$ was equal to $8.0 \pm 0.1$, while no buffer solution was added for $\mathrm{pH}$ adjustment.

\subsection{Chemical analysis}

For the determination of target compounds in aqueous samples, a High Performance Liquid Chromatography (HPLC, Waters Alliance 2695) system was used, interfaced by a Photodiode Array Detector (PDA, Waters 2996), and equipped with a C18 reverse phase column (Kinetex XBC18, $2.1 \mathrm{~mm} ; 2.6 \mathrm{~mm}$ internal diameter $\times 50 \mathrm{~mm}$ length) (Milford, MA, USA). An isocratic elution program with $0.1 \% \mathrm{H}_{3} \mathrm{PO}_{4}$ and $\mathrm{ACN}$ was also used. Samples were injected on the column with a full-loop injection of $100 \mu \mathrm{L}$, and PDA was set at 220, 230, 254, and $270 \mathrm{~nm}$, for LOS, VAL, parabens and SMX, respectively. BPA was measured using a fluorescence detector; the excitation wavelength was $280 \mathrm{~nm}$ and the emission wavelength was $305 \mathrm{~nm}$ (Darsinou et al., 2015).

For measuring the concentrations of MPs in coagulation experiments, the procedure described by Zhou et al. (2021) was followed with some modifications. The initial concentration of MPs was calculated based to the amount of PS or PE that was weighted in each flask. The concentrations of PS or PE in the supernatant at the end of the experiment were calculated based to the measurements of filters' weight after filtering known volumes of supernatant and drying at $60^{\circ} \mathrm{C}$ for $24 \mathrm{~h}$.

\subsection{Calculations and statistical treatment}

The removal of target micropollutants in sorption experiments and the removal of MPs in coagulationflocculation experiments were calculated according to Equation 1:

$$
\text { \%Removal }=\frac{C_{\text {in }}-C_{\text {out }}}{C_{\text {in }}} \times 100
$$

where, $C_{\text {in }}$ and $C_{\text {out }}$ are the concentrations of micropollutants or MPs at the start and at the end of the relevant experiment.
Statistical analysis was performed using Prism. T-test was used for comparing PS and PE removal during different coagulation experiments. All tests were run at the 0.05 significance level and all comparisons mentioned hereafter are based on the results of the statistical analysis.

\section{Results and discussion}

\subsection{Sorption of emerging contaminants to $P S$ and $P E$}

The sorption affinity of the eight (8) target organic micropollutants was initially examined in experiments containing PS, PE or no MPs (Control experiment). Based to the results of the Control experiments, it seems that none of the compounds are hydrolysed or sorbed to the glass of serum bottles. Similar observations for the stability of target micropollutants have also been reported in previous studies (la trou et al., 2017; Lincho et al., 2021). Concerning their sorption to MPs, important sorption was noticed for VAL and LOS, when PS was used as sorbent material (Figure 1). The sorption of these compounds to PS seems to be a slow process. After $72 \mathrm{~h}$, only $5 \%$ and $19 \%$ of VAL and LOS had been sorbed (Figure 1a), while their sorption was increased to $20 \%$ and $59 \%$, respectively at $168 \mathrm{~h}$ (Figure $1 \mathrm{~b}$ ).

This is the first study where the sorption affinity of these micropollutants is examined for PS and PE. Previous studies on the sorption of hydrophilic micropollutants to MPs have shown that physical interactions such as partitioning, electrostatic interactions, and intermolecular hydrogen bonding are the dominant mechanisms that affect this process while parameters such as the degree of crystallinity, rubbery domains, special groups and ageing of these materials as well as aqueous $\mathrm{pH}$ and chemical properties of the pollutants affect their sorption to MPs (Guo et al., 2019; Liu et al., 2019). Concerning VAL and LOS, their logKow values have been estimated to 4 , while their pKa have been estimated to 4.73 and 5.5, respectively (PubChem, 2021). At pH> 6.70, VAL exists almost exclusively as dianion, while LOS exist mainly under the anionic form (Tosco et al., 2008). For pH 7.5 that was applied during sorption experiments, the examined MPs have negative inherent charges (Liu et al., 2019). As a result, electrostatic interaction does not seem to be the determining factor for the adsorption behavior of VAL and LOS. Further experiments at different $\mathrm{pH}$ values and different concentrations of ionic strength are 
required to obtain a clear picture for the mechanisms affecting sorption of these micropollutants to PS and PE.

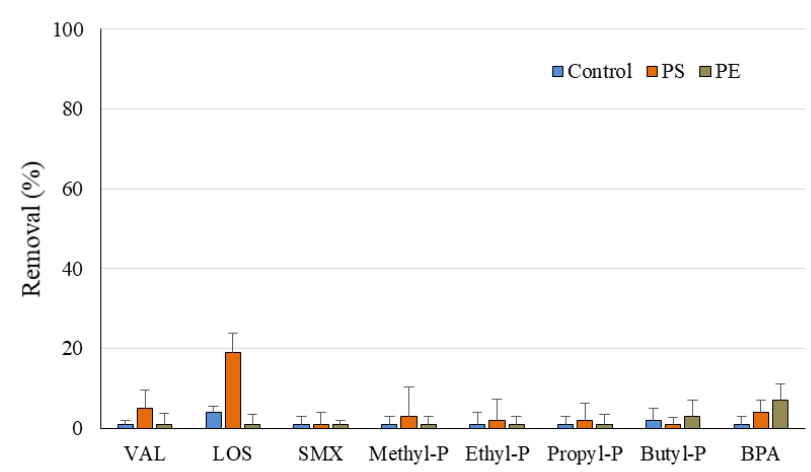

(a)

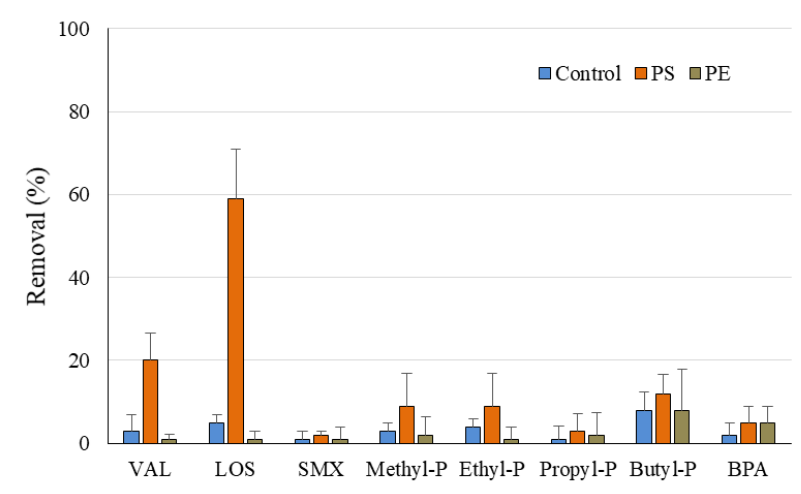

(b)

Figure 1. ( $a$ and $b$ ) Sorption of target organic micropollutants to polystyrene (PS) and polyethylene (PE) microplastics (MPs) after $72 \mathrm{~h}$ (a) and $168 \mathrm{~h}$ (b). In Control experiments, no MPs had been added

\subsection{Removal of PS and PE during coagulation-flocculation}

The $\mathrm{pH}$ of drinking water used in these experiments was equal to $8.0 \pm 0.1$ and remained stable during the experiment when no coagulant dose was added. On the other hand, the addition of $\mathrm{FeCl}_{3} \times 6 \mathrm{H}_{2} \mathrm{O}$ resulted to a decrease of $\mathrm{pH}$ at 7.56 and 7.11 for concentrations of 100 and $200 \mathrm{mg} \mathrm{L}^{-1} \mathrm{Fe}^{3+}$, respectively. This observation is due to the hydrolysis of $\mathrm{FeCl}_{3}$ and the release of hydrogen ions that lowering water $\mathrm{pH}$, as also confirmed by Duan and Gregory (2003). Similarly, the addition of $\mathrm{FeSO}_{4} \times 7 \mathrm{H}_{2} \mathrm{O}$ resulted to a further decrease of water $\mathrm{pH}$ at values lower than 6.75. Contrary to the above, the use of $\mathrm{MgSO}_{4} \times$ $7 \mathrm{H}_{2} \mathrm{O}$ increased slightly water $\mathrm{pH}$ to 8.13 and 8.24 for $\mathrm{Mg}^{2+}$ concentrations of 100 and $200 \mathrm{mg} \mathrm{L}^{-1}$ (Figure 2).

The removal efficiency of PS and PE in coagulation experiments is presented in Figures 3 and 4, respectively. Comparing the removal efficiencies of two MPs, it is observed that the removal of PS was higher than PE for all tested coagulants as well as in the experiments conducted in the absence of coagulant (Figures 3 and 4). This trend has also been observed in previous studies comparing the removal of two MPs during coagulation - flocculation process and it is probably due to the different density of tested materials (Zhou et al., 2021).
Concerning the removal of PS, in the absence of coagulants, PS was removed by $83.3 \pm 3.9 \%$ after 30 min of settling. This value is higher than that observed by Zhou et al (2021) who used a PS with density equal to 1.05 $\mathrm{g} / \mathrm{cm}^{3}$ and observed a removal equal of $50.78 \%$, when no coagulant was added. On the other hand, Xue et al. (2021) reported high PS removal efficiency (>86\% for PS particles of 45 and $90 \mu \mathrm{m}$ ) after $15 \mathrm{~min}$ settling. Apart from the characteristics of used MPs (e.g density), water matrix characteristics (specific conductance, cation concentrations etc.) seems also to affect their removal in settling experiments (Xue et al., 2021).

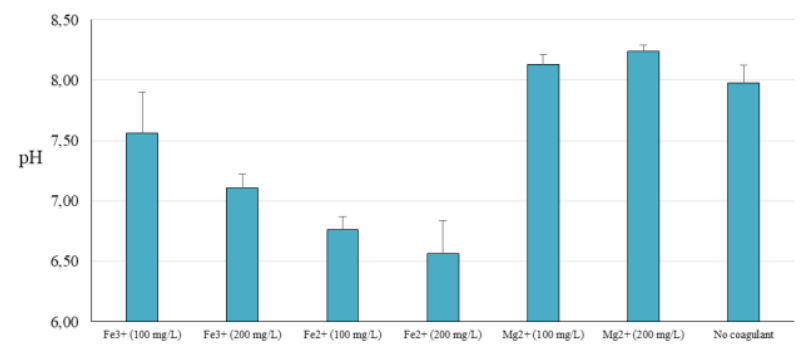

Figure 2. $\mathrm{pH}$ values at the end of different coagulation experiments with microplastics (MPs)

In the current study, the addition of $\mathrm{FeSO}_{4} \times 7 \mathrm{H}_{2} \mathrm{O}$ and $\mathrm{MgSO}_{4} \times 7 \mathrm{H}_{2} \mathrm{O}$ resulted to statistically significantly higher removal efficiencies of PS from water than those observed in the absence of coagulant. Specifically, when added $100 \mathrm{mg} \mathrm{L}^{-1}$ as $\mathrm{Fe}^{2+}$, the removal of PS was equal to $92.4 \pm 0.5 \%$, while in the presence of 100 and $200 \mathrm{mg} \mathrm{L}^{-1}$ as $\mathrm{Mg}^{2+}$, it was equal to $89.1 \pm 3.7 \%$ and $90.4 \pm 2.7 \%$, respectively (Figure 3 ). On the other hand, the addition of $\mathrm{Fe}^{3+}$ did not affect the removal efficiency of PS from water.

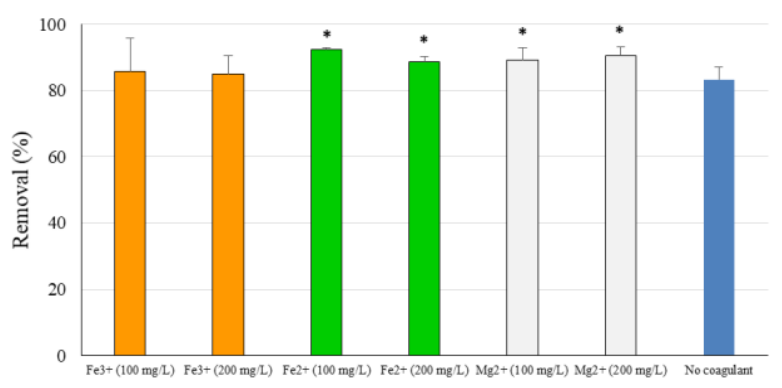

Figure 3. Polystyrene (PS) removal from water using different doses of coagulants. Statistically higher removal efficiencies are indicated with the use of an asterisk $\left({ }^{*}\right)$

Concerning PE, in the experiment where no coagulant was added, it was removed by $59.4 \pm 5.2 \%$. According to Figure 4, among tested coagulants, only $\mathrm{MgSO}_{4} \times 7 \mathrm{H}_{2} \mathrm{O}$ resulted to a statistical significant higher removal of $\mathrm{PE}$ $\left(72.1 \pm 3.6 \%\right.$ at $\left.200 \mathrm{mg} \mathrm{L}^{-1} \mathrm{Mg}^{2+}\right)$. On the other hand, negligible removal of PE was observed when $\mathrm{FeSO}_{4} \times 7 \mathrm{H}_{2} \mathrm{O}$ or $\mathrm{FeCl}_{3} \times 6 \mathrm{H}_{2} \mathrm{O}$ were used (Figure 4). This observation indicates that the addition of iron coagulants inhibited $\mathrm{PE}$ removal. The no (or even negative) removal of MPs during the addition of specific coagulants has also been observed in the literature and it is probably due to the formation of new disturbing particles (e.g., hydroxides) which are not 
settled. For instance, at $\mathrm{pH} 6.5$ and dosage of $0.07 \mathrm{mmol} / \mathrm{L}$ of $\mathrm{Fe}^{3+}$, Rajala et al. (2020) reported negative removal of MPs and increasing turbidity. Similarly, Xue et al. (2021) observed that the removal of $25-\mu \mathrm{m}$ microspheres was almost the same regardless of alum addition $(0$ or $30 \mathrm{mg} \mathrm{L}$ $\left.{ }^{1}\right)$; whereas the alum treatment performed more poorly in removing larger microspheres $(45-$ and $90-\mu \mathrm{m})$ than did alum-free sedimentation. It has been reported that larger MPs require proportionally larger coagulant flocs (Lapointe et al., 2020). However, due to the complexity of the water matrices, it is difficult to decipher the actual mechanisms behind the poorer removal of PE when iron coagulants were used and further investigation is needed.

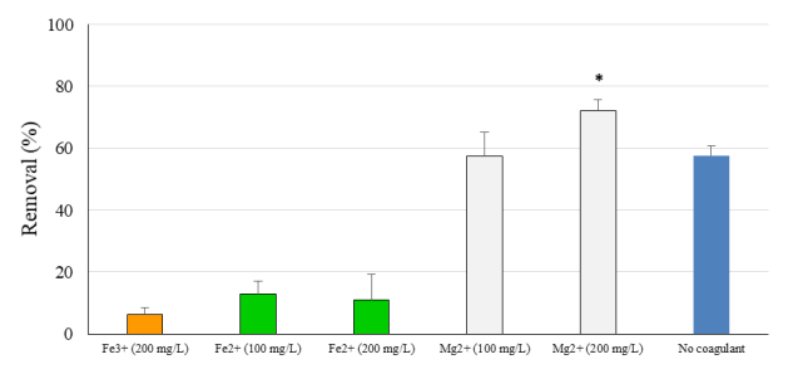

Figure 4. Polyethylene $(\mathrm{PE})$ removal from water using different doses of coagulants. Statistically higher removal efficiencies are indicated with the use of an asterisk $\left({ }^{*}\right)$.

Concerning the mechanisms that affect MPs removal during coagulation, it is known that charge neutralization is an important mechanism governing their removal. According to this process, the metal coagulants are hydrolyzed and the hydrolysates are adsorbed to the surface of the negatively-charged particles. This results to the neutralization of particles' surface, making them unstable and susceptible to flocculation (Duan, and Gregory, 2003). The higher removal of PS comparing to PE indicates that the charge neutralization intensity of PS system seems to be higher comparing to that of PE. Additionally, to charge neutralization, adsorption is also an important step in coagulation. The hydrolysis of coagulants can produce metal hydroxides with positive charge, which can adsorb surrounding particles and be eventually swept away by amorphous precipitation (Duan, and Gregory, 2003). According to the solubility diagram of different metal coagulants used, it seems that for $\mathrm{pH}$ higher than 6, amorphous metal hydroxides occur contributing also to the removal of negatively charged MPs from water (Stumm and Morgan, 1996).

\section{Conclusions}

Important differences were noticed on the sorption potential of organic micropollutants to PS and PE as well on the removal efficiency of these MPs during coagulation - flocculation experiments. According to the sorption experiments, most of the tested organic micropollutants were not sorbed to these MPs, while VAL and LOS were sorbed to PS by $20 \%$ and $59 \%$, respectively, after $168 \mathrm{~h}$ contact time. In coagulation experiments, an important part of PS and PE was removed after 30 min settling time in the absence of coagulant. The removal of PS was enhanced by the use of $\mathrm{MgSO}_{4} \times 7 \mathrm{H}_{2} \mathrm{O}$ or $\mathrm{FeSO}_{4} \times 7 \mathrm{H}_{2} \mathrm{O}$ as coagulants. Higher removal of PE was also achieved for the higher tested concentration of $\mathrm{MgSO}_{4} \times 7 \mathrm{H}_{2} \mathrm{O}$. Further experiments should be conducted to investigate the factors affecting sorption of VAL and LOS to studied MPs as well as the mechanisms governing MPs' removal during coagulation.

\section{Acknowledgments}

This research is co-financed by Greece and the European Union (European Social Fund- ESF) through the Operational Programme "Human Resources Development, Education and Lifelong Learning 2014-2020" in the context of the project "Microplastics in Wastewater Treatment Plants: Occurrence and Fate" (MIS 5048204)».

\section{References}

Andrady A.L. (2011). Microplastics in the marine environment, Marine Pollution Bulletin, 62, 1596-1605.

Arukula D., Prem P., Tanwi P., Hariraj S., Vijay L.M. and Brijesh K.M. (2018). Treatment of tannery wastewater using aluminium formate: Influence of the formate over sulphatebased coagulant, Global Nest Journal, 20, 458-464.

Ben-David E.A., Habibi M., Haddad E., Hasanin M., Angel D.L., Booth A.M. and Sabbah I. (2020). Microplastic distributions in a domestic wastewater treatment plant: Removal efficiency, seasonal variation and influence of sampling technique, Science of the Total Environment, 752, 141880.

Bratby J. (2016). Coagulation and Flocculation in Water and Wastewater Treatment, $3^{\text {rd }}$ edition, IWA.

Chae Y. and An Y.J. (2017). Effects of micro-and nanoplastics on aquatic ecosystems: Current research trends and perspectives, Marine Pollution Bulletin, 124, 624-632.

Cheng Y.L., Kim J.-G., Kim H.-B., Choi J.S., Fai Tsang Y. and Baek K. (2021). Occurrence and removal of microplastics in wastewater treatment plants and drinking water purification facilities: A review, Chemical Engineering Journal, 410, 128381.

Darsinou B., Frontistis Z., Antonopoulou M., Konstantinou I. and Mantzavinos D. (2015). Sono-activated persulfate oxidation of bisphenol A: Kinetics, pathways and the controversial role of temperature, Chemical Engineering Journal, 280, 623633.

Dayarathne H.N.P., Angove M.J., Aryal R., Abuel-Naga H. and Mainali B. (2021). Removal of natural organic matter from source water: Review on coagulants, dual coagulation, alternative coagulants, and mechanisms, Journal of Water Process Engineering, 40, 101820.

Duan J. and Gregory J. (2003). Coagulation by hydrolysing metal salts, Advances in Colloid and Interface Science, 100-102, 475-502.

Gatidou G., Arvaniti O.S. and Stasinakis A.S. (2019). Review on the occurrence and fate of microplastics in Sewage Treatment Plants, Journal of Hazardous Materials, 367, 504512.

Guo X., Chen C. and Wang J. (2019). Sorption of sulfamethoxazole onto six types of microplastics, Chemosphere, 228, 300-308.

latrou E.I., Gatidou G., Damalas D., Thomaidis N.S. and Stasinakis A.S. (2017). Fate of antimicrobials in duckweed Lemna minor wastewater treatment systems, Journal of Hazardous Materials, 330, 116-126. 
Jiang J.-Q., Stanford C. and Mollazeinal A. (2012). The application of ferrate for sewage treatment: Pilot-to full-scale trials, Global Nest Journal, 14, 93-99.

Karapanagioti H.K., Ogata Y. and Takada H. (2010). Eroded plastic pellets as monitoring tools for polycyclic aromatic hydrocarbons (PAH): Laboratory and field studies, Global Nest Journal, 12, 327-334.

Kaur B. and Dulova N. (2020). UV-assisted chemical oxidation of antihypertensive losartan in water, Journal of Environmental Management, 261, 110170.

Lapointe M., Farner J.M., Hernandez L.M. and Tufenkji N. (2020). Understanding and improving microplastic removal during water treatment: impact of coagulation and flocculation, Environmental Science and Technology, 54, 87198727.

Lincho J., Martins R.C. and Gomes J. (2021). Paraben compounds-part i: An overview of their characteristics, detection, and impacts, Applied Sciences (Switzerland), 11, 2307.

Liu G., Zhu Z., Yang Y., Sun Y., Yu F. and Ma J. (2019). Sorption behavior and mechanism of hydrophilic organic chemicals to virgin and aged microplastics in freshwater and seawater, Environmental Pollution, 246, 26-33.

Ma B., Xue W., Hu C., Liu H., Qu J.and Li L. (2019). Characteristics of microplastic removal via coagulation and ultrafiltration during drinking water treatment, Chemical Engineering Journal, 359, 159-167.

Murphy F., Ewins C., Carbonnier F. and Quinn B. (2016). Wastewater treatment works (WWTW) as a source of microplastics in the aquatic environment, Environmental Science Technology, 50, 5800-5808.

Paul-Pont I., Tallec K., Gonzalez-Fernandez C., Lambert C., Vincent D., Mazurais D., Zambonino-Infante J.L., Brotons G., Lagarde F., Fabioux C., Soudant P. and Huvet A. (2018). Constraints and priorities for conducting experimental exposures of marine organisms to microplastics, Frontiers in Marine Science, 5, 252.

Pivokonský M., Pivokonská L., Novotná K., Čermáková L. and Klimtová M. (2020). Occurrence and fate of microplastics at two different drinking water treatment plants within a river catchment, Science of the Total Environment, 741,140236.

PubChem (2021). Chemical and physical properties of Valsartan (https://pubchem.ncbi.nlm.nih.gov/compound/60846, last access 17.06.2021) and Losartan (https://pubchem.ncbi.nlm. nih.gov/compound/3961, last access 17.06.2021).

Rajala K., Grönfors O., Hesampour M. and Mikola A. (2020). Removal of microplastics from secondary wastewater treatment plant effluent by coagulation/flocculation with iron, aluminum and polyamine-based chemicals, Water Research, 183, 116045.

Ramirez Arenas L., Ramseier Gentile S., Zimmermann S. and Stoll S. (2020). Coagulation of $\mathrm{TiO}_{2}, \mathrm{CeO}_{2}$ nanoparticles, and polystyrene nanoplastics in bottled mineral and surface waters. Effect of water properties, coagulant type, and dosage, Water Environment Research, 92, 1184-1194.

Rubin B.S. (2011). Bisphenol A: an endocrine disruptor with widespread exposure and multiple effects, Journal of Steroid Biochemistry and Molecular Biology, 127, 27-24.

Singla M., Díaz J., Broto-Puig F. and Borrós S. (2020). Sorption and release process of polybrominated diphenyl ethers (PBDEs) from different composition microplastics in aqueous medium: Solubility parameter approach, Environmental Pollution, 262, 114377.

Stumm W. and Morgan J.J. (1996). Aquatic Chemistry: Chemical Equilibria and Rates in Natural Waters, $3^{\text {rd }}$ edition, Wiley.

Tosco P., Rolando B., Fruttero R., Henchoz Y., Martel S., Carrupt P.-A. and Gasco A. (2008). Physicochemical profiling of sartans: A detailed study of ionization constants and distribution coefficients, Helvetica Chimica Acta, 91, 468-482.

Tziourrou P., Kordella S., Ardali Y., Papatheodorou G. and Karapanagioti H.K. (2021). Microplastics formation based on degradation characteristics of beached plastic bags, Marine Pollution Bulletin, 169, 112470.

Wei F., Mortimer M., Cheng H., Sang N. and Guo L.-H. (2021). Parabens as chemicals of emerging concern in the environment and humans: A review, Science of the Total Environment, 778, 146150.

Xue J., Peldszus S., Van Dyke M.I. and Huck P.M. (2021). Removal of polystyrene microplastic spheres by alum-based coagulation-flocculation-sedimentation (CFS) treatment of surface waters, Chemical Engineering Journal, 422, 130023.

Yu H., Yang B., Waigi M.G., Li Z. and Hu X. (2020). The effects of functional groups on the sorption of naphthalene on microplastics, Chemosphere, 261, 127592.

Zhou G., Wang Q., Li J., Li Q., Hu J., Ye Q., Wang Y., Shu S. and Zhang J. (2021). Removal of polystyrene and polyethylene microplastics using PAC and $\mathrm{FeCl}_{3}$ coagulation: Performance and mechanism, Science of the Total Environment, 752, 141837. 